Article

\title{
Genome-Wide Identification, Characterization and Expression Patterns of the Pectin Methylesterase Inhibitor Genes in Sorghum bicolor
}

\author{
Angyan Ren ${ }^{1,+}{ }^{+}$, Rana Imtiaz Ahmed ${ }^{1,+}$, Huanyu Chen ${ }^{2,3}$, Linhe Han ${ }^{1}$, Jinhao Sun ${ }^{1}$, \\ Anming Ding ${ }^{1}$, Yongfeng Guo ${ }^{1}(\mathbb{D})$ and Yingzhen Kong ${ }^{1,2, *}$ \\ 1 Key Laboratory for Tobacco Gene Resources, Tobacco Research Institute, Chinese Academy of Agricultural \\ Sciences, Qingdao 266101, China; ray0918@163.com (A.R.); imtiazheaven@yahoo.com (R.I.A.); \\ hanlinhe1993@163.com (L.H.); 18253805901@163.com (J.S.); dinganming@caas.cn (A.D.); \\ guoyongfeng@caas.cn (Y.G.) \\ 2 College of Agronomy, Qingdao Agricultural University, Qingdao 266108, China; chykyr@163.com \\ 3 Center for Agricultural Resources Research, Institute of Genetics and Developmental Biology, Chinese \\ Academy of Science, Shijiazhuang 050021, China \\ * Correspondence: kongyzh@qau.edu.cn \\ + These authors contributed equally to this work.
}

Received: 5 August 2019; Accepted: 24 September 2019; Published: 26 September 2019

check for updates

\begin{abstract}
Cell walls are basically complex with dynamic structures that are being involved in several growth and developmental processes, as well as responses to environmental stresses and the defense mechanism. Pectin is secreted into the cell wall in a highly methylesterified form. It is able to perform function after the de-methylesterification by pectin methylesterase (PME). Whereas, the pectin methylesterase inhibitor (PMEI) plays a key role in plant cell wall modification through inhibiting the PME activity. It provides pectin with different levels of degree of methylesterification to affect the cell wall structures and properties. The PME activity was analyzed in six tissues of Sorghum bicolor, and found a high level in the leaf and leaf sheath. PMEI families have been identified in many plant species. Here, a total of 55 pectin methylesterase inhibitor genes (PMEIs) were identified from S. bicolor whole genome, a more detailed annotation of this crop plant as compared to the previous study. Chromosomal localization, gene structures and sequence characterization of the PMEI family were analyzed. Moreover, cis-acting elements analysis revealed that each PMEI gene was regulated by both internal and environmental factors. The expression patterns of each PMEI gene were also clustered according to expression pattern analyzed in 47 tissues under different developmental stages. Furthermore, some SbPMEIs were induced when treated with hormonal and abiotic stress. Taken together, these results laid a strong foundation for further study of the functions of SbPMEIs and pectin modification during plant growth and stress responses of cereal.
\end{abstract}

Keywords: PMEI; gene structure; cis-acting element; gene expression; qRT-PCR; cell wall; Sorghum bicolor; expression patterns

\section{Introduction}

Plant cell walls are composed of high-molecular-weight polysaccharides including cellulose, hemicellulose, pectin and several glycosylated proteins [1]. These complexes with dynamic structures play important roles in several physiological and developmental processes [2]. Pectin is the most complicated polysaccharide component in plant cell walls and mainly contains homogalacturonan (HG), rhamnogalacturonan I (RG I), rhamnogalacturonan II (RG II) and xylogalacturonan (XGA) [2,3]. The ratio between these four polysaccharides is variable in pectin polymers, but HG is the most 
abundant one constituting about 65\% [3]. The HG domain comprises $\alpha$-D-(1-4)-galacturonic backbone and can be methyl-esterified in general. The pectin matrix is synthesized in a highly methylesterified form in the Golgi apparatus and then secreted into cell walls, where it is de-methylesterified by pectin methylesterase (PME) [3]. Such events may bring changes in the structural and functional properties of cell walls, which is vital to pollen development, pollen tube growth, organ aging, fruit ripening and plant defense i.e., senescence, wounding, biotic and abiotic stress [4-10]. Moreover, de-methylesterified pectin produces the pectic acid that can bind to extracellular $\mathrm{Ca}^{2+}$ to synthesize pectinate, which helps in the stiffening of cell walls and allows the cells to grow gradually.

The fact that PME activity is regulated by the pectin methylesterase inhibitor (PMEI) was first discovered in Actinidia chinensis [11]. Since then, seventy-one PMEI-related genes have been annotated in Arabidopsis thaliana, while some of them have been identified to inhibit the PME activity in vivo [12-14]. A total of 152 amino acid (aa) residues of PMEI were purified from kiwi fruit through protein chemical analysis techniques. PMEI is a glycoprotein, proposing a much more acidic nature of amino acids in protein sequences. It is active against plant PMEs to form a 1:1 non-covalent complex, while the stability of the complex is strongly $\mathrm{pH}$-dependent $[15,16]$. In Arabidopsis, AtPME17 is regulated by AtPMEI4 and SBT3.5 (subtilisin-like serine protease), which is being involved in mediating the changes in pectin properties and accurate root growth [17]. Furthermore, detailed biochemical characterization verified that AtPMEI7 regulates the activity of AtPME3 in a pH-dependent manner [15]. The interconversion between PME and PMEI usually determines cell-cell adhesion, cell wall porosity and elasticity. It also acts as a source of signaling molecules, released upon cell wall stress. Therefore, the identification of PME and PMEI family members in different species would make great biological significances and benefits for fully understanding the mechanism of cell wall modification.

Recent studies demonstrated the crucial role of PMEI in the proclamation of cell and organ size, cell growth acceleration [18] and pollen tube development [5,6,8]. The overexpression of AtPMEI3 in transgenic lines in Arabidopsis exhibited higher methyl esterification of HG in the meristem tissues and exaggerated the phyllotaxis pattern of leaves [19]. Additionally, the overexpression of AtPMEI5 in Arabidopsis thaliana caused twisted stems, organ fusion and increased germination rate [20]. Whereas, AtPMEI6 has been identified as a necessary protein involved in the regulation of mucilage synthesis and extrusion from seed coat in Arabidopsis [14]. In flax (Linum usitatissimum), 83 gene members of the PMEI family have been identified, which may participate in the formation and modification of pectin in cell walls to influence phloem fibers elongation [21]. It has been demonstrated that SolyPMEI in tomato specifically expresses in fruit development where its protein interacts with fruit-specific SolyPME1 to regulate the degree of methyl esterification [22]. Intriguingly, preliminary biochemical and molecular characterization of VvPMEI1 in grapevine also elaborated its role in grape berry development [23]. The PMEI purified from kiwi fruit has been utilized to detect residual PME activity, to inactivate PME in fruit products and is also used as an adjuvant in the manufacturing of vegetable-derived products $[11,24]$.

Based on previous researches, PMEI genes are not only essential in plant development but also have physiological significance in plant abiotic stress tolerance and disease resistance $[25,26]$. For example, CaPMEI1 from pepper, which is confined in the xylem tissues of vascular bundles, acts as an antifungal protein [4]. It is well demonstrated that the purified recombinant CaPMEI1 protein not only exhibits an inhibitory effect on PME but also plays a role in providing resistance to bacterial pathogens and tolerance to drought and oxidative stress [4]. The overexpression of PMEI from Actinidia chinensis in wheat showed a reduced PME activity and a significant increase in the degree of methylesterification [27]. The transgenic line of AcPMEI in wheat also showed improved fungal pathogen resistance by altering the methylesterification of pectin cell wall, which acts as a broad spectrum resistance to diseases $[27,28]$. Thus, the previous studies demonstrate the significance of PMEI in biological and physiological processes, as well as in stress resistance.

Although PMEI families have been reported in many plant species, but only a few studies have been performed on its role in monocots. Up until now, 37 PMEIs were identified in sorghum in previous 
studies [29]. To gain better insights into the functional of PMEI family, a systematic comparative analysis at the whole-genome level was performed. In this study, 55 PMEIs protein members in Sorghum bicolor were identified and characterized, with addition of 18 new members. The evolution relationships, along with chromosomal and subcellular localization were analyzed. We also detected the gene ontology (GO) category annotations, and protein-protein interaction. The expression patterns of different tissues at different growth and developmental stages were obtained through transcriptome microarray data. The responses of SbPMEIs to hormone and abiotic stress were detected by quantitative real-time PCR (qRT-PCR). This study will be supportive for further functional characterization of this gene family in sorghum as well as other monocot crops.

\section{Materials and Methods}

\subsection{Plant Materials and PME Activity Analysis}

Sorghum (Sorghum bicolor (L.) Moench) seeds were germinated at $24+1{ }^{\circ} \mathrm{C}$ under a 16 hour (h) light $/ 8 \mathrm{~h}$ dark cycle and seedlings were then transferred to pots in glasshouse conditions. One week after anthesis, the tissues used in the analysis were collected to extract protein for PME activity analysis.

Total protein extracts were obtained using a One-Step Plant Active Protein Extraction Kit (Sangon Biotech, C510004, Taiwan, China) and calibrated with Easy Protein Quantitative Kit (Bradford; TransGen, DQ101, Beijing, China) using bovine serum albumin (BSA) standard solution and Commas Brilliant Blue solution. The same amount of protein from different tissues were used to analyze. The detailed method was followed as previously reported [12]. Protein extracts $(10 \mu \mathrm{g})$ in a same volume $(20 \mu \mathrm{L})$ were loaded in to the $4 \mathrm{~mm}$-diameter wells in $1 \%$ agarose gels containing citrus fruit pectin $(0.1 \%$ $\left(w / v ; \geq 85 \%\right.$ esterified, Sigma-Aldrich, P9561, Germany), citric acid $(12.5 \mathrm{mM})$ and $50 \mathrm{mM} \mathrm{Na} 2 \mathrm{HPO}_{4}$, having $\mathrm{pH}$ 6.5. The gels were kept overnight at $28^{\circ} \mathrm{C}$ followed by staining for $1 \mathrm{~h}$ with $0.05 \%(w / v)$ ruthenium red and washed for $4 \mathrm{~h}$ in water. The stained gels were photographed and the intensity of staining quantified with ImageJ software [14]. Measurements were performed in triplicate and data were normalized with the tissue stem area set to one.

\subsection{Identification of SbPMEI Members and Sequence Characterization}

Previously reported AtPMEI in Arabidopsis thaliana and OsPMEI in Oryza sativa protein sequences were retrieved from The Arabidopsis Information Resource (TAIR: https:/www.arabidopsis.org/) and Rice Genome Annotation Project (http://rice.plantbiology.msu.edu/index.shtml), respectively [29]. Using the Arabidopsis and rice, full-length PMEI protein and homeodomain amino acid sequences, PLASTP was performed in the sorghum genome database (JGI: https://phytozome.jgi.doe.gov/pz/portal. $\mathrm{html})$. Furthermore, produced Stockholm files by aligning AtPMEI and OsPMEI protein sequences with MAFFT v7 for building a hidden Markov model (HMM) profile, were applied to search the sorghum database [30]. To confirm the presence of the PMEI domain, all the candidate sequences were submitted to Pfam 32.0 (http://pfam.xfam.org/) based on an HMM annotated PMEI domain as PF04043 and were analyzed through SMART (http://smart.embl-heidelberg.de/).

Genome sequences, coding sequences (CDS) and chromosome location of PMEIs were also obtained from the JGI database. Physicochemical properties of each SbPMEI gene were calculated by ExPASy ProtParam tool (https://web.expasy.org/protparam/), including the amino acids length, molecular weight (MW), isoelectric point ( $\mathrm{pI}$ ) and open reading frame (ORF). The subcellular locations were predicted using WOLF POSRT II (https://www.genscript.com/psort.html) and Plant-mPLoc (http://www.csbio.sjtu.edu.cn/bioinf/plant-multi/).

\subsection{Phylogenetic Analysis, Chromosome Location and Tandem Gene Duplication}

Multiple sequences alignment of protein sequences of AtPMEIs, OsPMEI and putative SbPMEIs members was performed using Clustal W (https://www.genome.jp/tools-bin/clustalw) under the default setting, while the phylogenetic tree was constructed with MEGA v6.0 using the maximum likelihood 
(ML) and the neighbor-joining (NJ) method with 1000 bootstrap replicates [31]. The chromosome location information was derived from the JGI database. The online software MapGene2 (http: //mg2c.iask.in/mg2c_v2.0/) was adopted to determine the chromosomal location of SbPMEI genes. The gene names were nominated according to the position on each chromosome from the top to bottom [31]. Gene cluster was defined as adjacent genes from one gene family separated by two or more genes in a $100 \mathrm{~kb}$ region within an individual chromosome and tandem gene duplication is the genes similarity within $70 \%$ in one gene cluster [32]. The gene similarities in a gene cluster of sorghum were detected according to EMBOSS (https://www.ebi.ac.uk/Tools/psa/).

\subsection{Gene Structure, GO Analysis and Protein-Protein Interaction Analysis}

The gene structures of the SbPMEI genes were illustrated with Gene Structure Display Server (GSDS: http://gsds.cbi.pku.edu.cn/) [33], by comparing CDS sequences with their corresponding genomic DNA sequences. Each SbPMEI, AtPMEI and OsPMEI protein was searched in InterproScan 5 (http://www.ebi.ac.uk/interpro/) for GO category annotation [34]. The predicated protein-protein interaction (PPI) networks were generated from the STRING database [35], by submitting SbPMEI proteins independently and jointly.

\subsection{Cis-Acting Elements Analysis}

According to the chromosome location of SbPMEIs, the $1.5 \mathrm{~kb}$ upstream region preceding the start codon of sorghum PMEI genes were cut out. Cis-acting element analysis in this region was detected using online tool PlantCARE (http://bioinformatics.psb.ugent.be/webtools/plantcare/ $\mathrm{html} /$ ) [36]. Then, the figures were drawn by using Adobe Illustrator software according to the collected information.

\subsection{Expression Patterns of Sorghum PMEI Genes}

Expression data of each SbPMEI gene in 47 tissue samples at different growth and developmental stages were obtained from PhytoMine (https://phytozome.jgi.doe.gov/phytomine/begin.do) [37]. With a Perl script, the microarray data were compiled into a database, then analyzed with the HemI program using the Euclidean distance and the hierarchical clustering method of complete linkage cluster to display the relative expression level of sorghum PMEI genes.

\subsection{Abiotic Stress Treatments, RNA Isolation and qRT-PCR Analysis}

For abiotic stress treatments, 14 day-old seedlings were transferred from the half-strength of solid Murashige and Skoog (MS) medium to $200 \mathrm{ml}$ half-strength of MS solution, which contained each $100 \mu \mathrm{M}$ of methyl jasmonic (MeJA), $100 \mu \mathrm{M}$ gibberellin A3 (GA3), $100 \mu \mathrm{M}$ of abscisic acid (ABA), 25\% $(w / v)$ polyethylene glycol (PEG, MW 6000) and $250 \mathrm{mM} \mathrm{NaCl}, 100 \mathrm{mM}$ hydrogen peroxide $\left(\mathrm{H}_{2} \mathrm{O}_{2}\right)[4,38]$. The plant shoots were collected after treated $0 \mathrm{~h}, 2 \mathrm{~h}, 4 \mathrm{~h}, 8 \mathrm{~h}$ and $12 \mathrm{~h}$, then frozen quickly in liquid nitrogen and stored at $-80^{\circ} \mathrm{C}$ for RNA extraction.

Total RNA was extracted from each sample using TaKaRa MiniBEST Plant RNA Extraction Kit (Code No. 9769). The first cDNA strand was synthesized from $2 \mu \mathrm{g}$ total RNA using the TransScript One-Step gDNA Removal and cDNA Synthesis SuperMix kit (TransGen, Code No. AT311) and then diluted 1:40 with $\mathrm{ddH}_{2} \mathrm{O}$ used as templates for qRT-PCR. The TB Green ${ }^{\circledR}$ Premix Ex Taq ${ }^{\mathrm{TM}}$ II (Tli RNaseH Plus; Takara, Code No. RR820A, Takara, Japan) was used to detect the gene expression. EIF4A1 gene (Sobic.004G039400.2) was selected as the sorghum housekeeping gene to normalize the various samples [39]. The gene-specific primers for qRT-PCR were designed with the NCBI Primer-BLAST tool. qRT-PCR assay was performed by ABI 7500 Real-Time System. $2^{-\Delta \Delta C T}$ method was used to analyze the gene relative expression level compared with treatment at $0 \mathrm{~h}$ [40]. Primers used in this study are listed in the Supplementary File 1. 


\section{Results}

\subsection{PME Activity Analysis of Six Tissues From Sorghum Bicolor}

Inhibiting the enzyme activity of pectin methyl-esterase is the main function of the PMEI protein, by forming a 1:1 non-covalent complex $[2,3,11]$. In order to investigate the sorghum cell walls undergoes PME-mediated de-methylesterification, the PME activity of six sorghum tissues was detected. Total soluble proteins isolated from six tissues and calibrated using the BSA standard solution. The same amount of proteins in the same volume was used for a PME activity assay. Notably, leaf and leaf sheath possessed relatively higher PME activity, while the lowest activity was detected in stem tissues, suggesting that pectin modification occurred in each tissue with different levels (Figure 1).

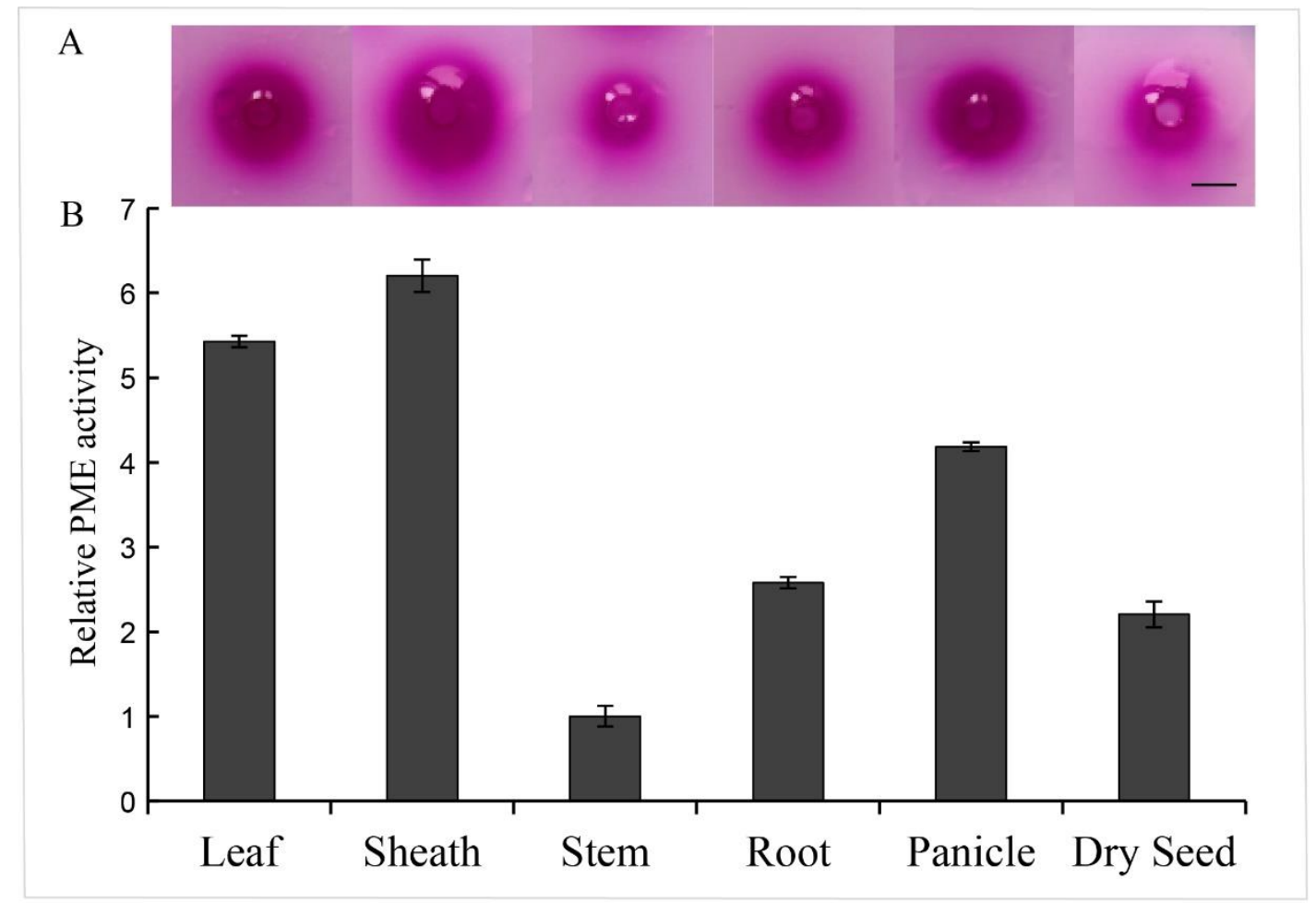

Figure 1. Relative pectin methylesterase (PME) activity analysis of six sorghum tissues. Total protein was extracted from six tissues of sorghum to analyze the PME activity. (A) Stained gels of the PME reaction using ruthenium red, the red halo means the de-methylesterificated pectin by PME. Scale bar $=0.5 \mathrm{~cm}$. (B) The relative PME activity with the tissue stem area set to one, based on the halo area of stained gel.

\subsection{Identification, Chromosome Location and Tandem Gene Duplicates of PMEI Genes in Sorghum}

Each PMEI protein sequence of Arabidopsis and rice were taken for BlastP in JGI database to obtain potential PMEI proteins of sorghum. Redundant sequences were removed manually. On the other way, the HMM (PF04043) profile was searched against the related protein database. To further confirm the reliability of these candidate members, each sequence was analyzed by PFAM and SMART tools to ensure the presence of the PMEI homeodomain and without the PME domain. Finally, 55 members, containing the PMEI domain, were identified as PMEIs in the sorghum whole-genome (Figure 2). Compared with the previous study, 18 more sorghum PMEI members were detected in the whole-genome [29].

Gene family expansion in the genome is very important from an evolutionary point of view of the plant. To identify gene clusters and investigating gene tandem duplicates of SbPMEI, the gene map of the chromosome is necessary. We employed online software MapGene2 to determine the chromosomal 
location of SbPMEI genes and the chromosomal map was generated by using local sequence databases of the complete genome. The genes names were nominated as SbPMEI1-55 according to the position on each chromosome from the top to bottom (Figure 2). All of the $55 \mathrm{SbPMEI}$ genes were mapped to 10 chromosomes of sorghum, as the genes were distributed among all chromosomes unevenly (Figure 2). Chromosomes 1, 3 and 4 were found to carry over seven SbPMEI genes (8, 8 and 10, respectively). Only two genes were located on chromosome 9, SbPMEI50 and SbPMEI51 (Figure 2).

Tandem duplicates were defined by the distance between two or more genes to be less than $100 \mathrm{~kb}$ (gene cluster) and the sequence similarity of these genes kept within 70\% [32]. Fifteen gene pairs have been detected belonging to gene clusters on eight chromosomes except for chromosomes 5 and 9, which might make up tandem duplications (Figure 2). After alignment, through the EMBOSS Needle tool, the similarity of four gene pairs exceeded from 70\% (SbPMEI11 and SbPMEI12; SbPMEI39, SbPMEI40 and SbPMEI41; SbPMEI47 and SbPMEI49; SbPMEI54 and SbPMEI55), which were regarded as tandem duplicates. Detail information on sequence similarity of paralogous pairs is shown in the Supplementary File 2.

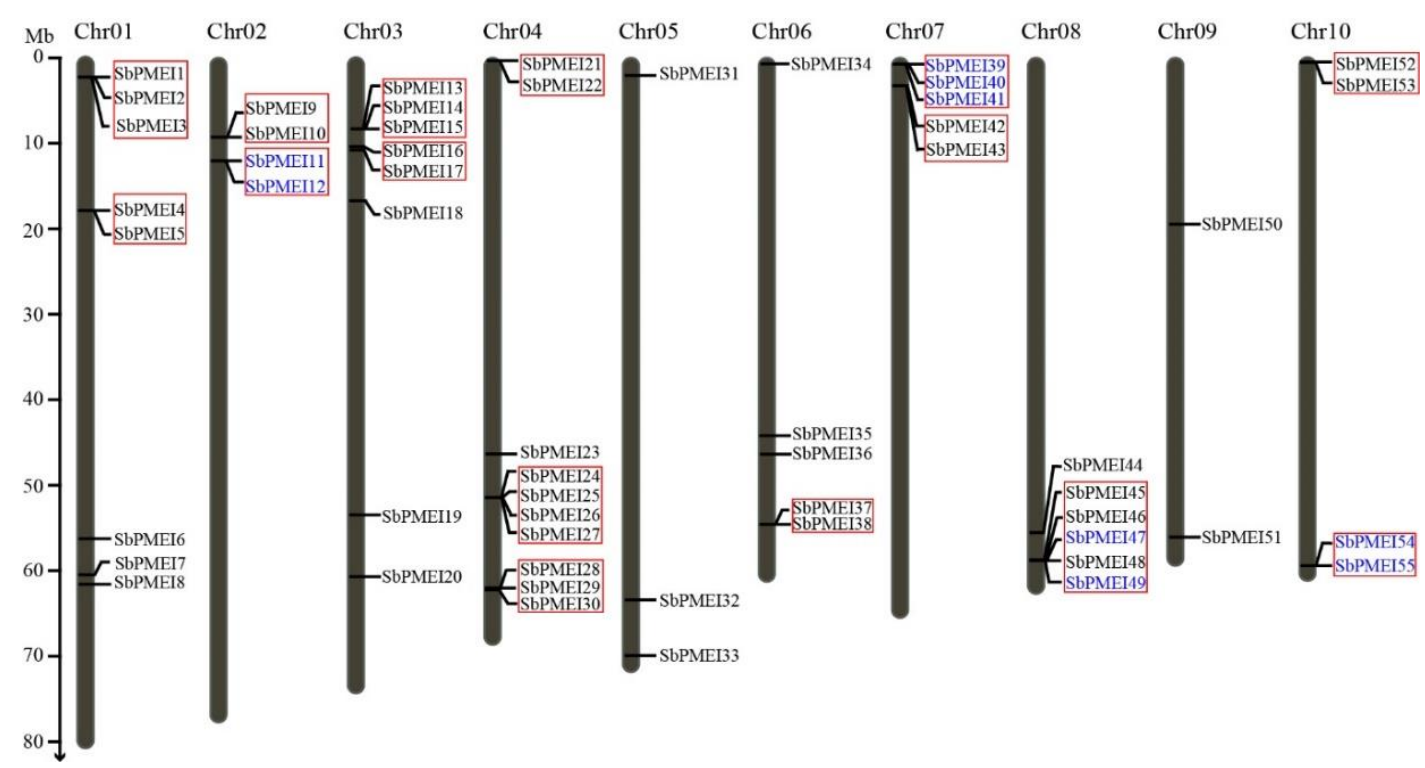

Figure 2. PMEI genes' distribution on sorghum chromosomes. Red rectangles represent the gene clusters, with the distance of SbPMEIs in a $100 \mathrm{~kb}$ region within an individual chromosome. The tandem gene duplications are indicated by blue colored names. Chr: Chromosome.

\subsection{Phylogenetic Analysis and Sequence Characterizations}

To investigate the evolution of PMEI proteins, the ML tree was generated based on the multiple sequence alignment of 71 Arabidopsis, 49 rice and $55 \mathrm{SbPMEI}$ full-length protein sequences. We found PMEI members fell into five clades (Figure 3A,B). Most members in Clade 4 and Clade 5 belonged to rice and sorghum (monocot clade), while Clade 1-3 (dicot clade) contained a large part of Arabidopsis PMEIs. In order to investigate the homology between SbPMEIs, 55 protein sequences were aligned and a phylogenetic tree of all the full-length protein sequences was constructed using the MEGA v6.0 program by the neighbor-joining (NJ) method (Figure 3C). Based on phylogeny, SbPMEIs were classified into three subfamilies (subfamily I, II and III) according to the clusters exhibited on the tree (Figure 3C), while each subfamily contained 20, 18 and 17 members, respectively (Table 1). The protein sequences (Supplementary File 3), CDS (Supplementary File 4) and genomic sequences (Supplementary File 5) for the 72 members were downloaded from the JGI database. 

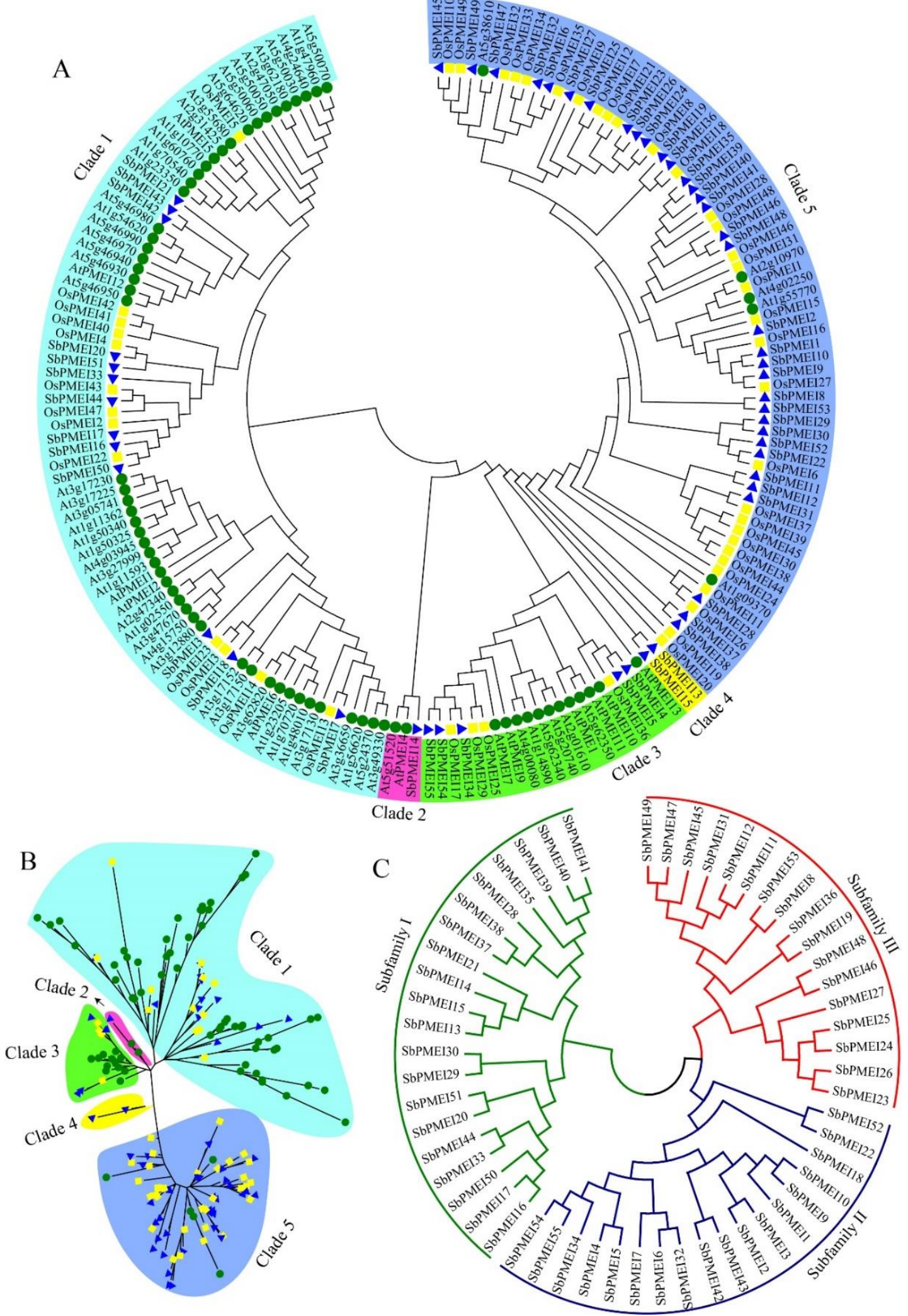

Figure 3. The phylogenetic tree analysis. (A) and (B) Maximum likelihood (ML) tree of PMEI proteins of Sorghum bicolor (blue triangle), Arabidopsis thaliana (green circle), and Oryza sativa (yellow square) fell into five clades. (C) Three subfamilies were evolved based on the neighbor-joining (NJ) tree of 55 S. bicolor PMEI proteins. 
Table 1. Characteristics of fifty-five PMEIs identified in the S. bicolor genome.

\begin{tabular}{|c|c|c|c|c|c|c|c|c|c|c|}
\hline \multirow{2}{*}{ Gene Name } & \multirow{2}{*}{ Sequence ID } & \multirow{2}{*}{ Subfamily } & \multirow{2}{*}{$\begin{array}{l}\text { Signal } \\
\text { Position }\end{array}$} & \multirow{2}{*}{ ORF (bp) } & \multicolumn{2}{|r|}{ Subcellular Localization } & \multicolumn{3}{|c|}{ Predicted Features } & \multirow{2}{*}{$\begin{array}{l}\text { No. of } \\
\text { Intron }\end{array}$} \\
\hline & & & & & Plant-mPLoc & WOLF PSORT & Length (aa) & NM (kDa) & pI & \\
\hline SbPMEI1 & Sobic.001G024300 & II & $1-24$ & 564 & C.M & chlo: 9 , extr: 4 & 187 & 19.30 & 5.48 & 0 \\
\hline SbPMEI2 & Sobic.001G024400 & II & $1-31$ & 588 & C.M & chlo: 9 , extr: 4 & 195 & 20.85 & 4.68 & 0 \\
\hline SbPMEI3 & Sobic.001G024900 & II & $1-34$ & 723 & C.M, Nuc & chlo: 14 & 240 & 24.76 & 8.86 & 0 \\
\hline SbPMEI4 & Sobic.001G198700 & II & $1-26$ & 720 & C.M, Nuc & chlo: 9 , vacu: 3 , mito: 1 & 239 & 24.29 & 5.09 & 0 \\
\hline SbPMEI5 & Sobic.001G198800 & II & $1-24$ & 672 & C.M, Nuc & chlo: 12 , mito: 1 & 223 & 22.49 & 5.87 & 0 \\
\hline SbPMEI6 & Sobic.001G288400 & II & $1-23$ & 660 & C.M & chlo: 11 , extr: 2 & 219 & 21.93 & 8.83 & 0 \\
\hline SbPMEI7 & Sobic.001G323801 & II & $1-20$ & 681 & C.M & chlo: 11 , nucl: 1 , mito: 1 & 227 & 22.88 & 8.72 & 0 \\
\hline SbPMEI8 & Sobic.001G328900 & III & $1-19$ & 714 & Nuc & extr: 12, vacu: 1 & 231 & 24.31 & 8.18 & 1 \\
\hline SbPMEI9 & Sobic.002G091200 & I & $1-25$ & 768 & C.M & chlo: 13 & 255 & 25.91 & 4.69 & 0 \\
\hline SbPMEI10 & Sobic.002G091300 & I & $1-22$ & 948 & Nuc & chlo: 7 , extr: 6 & 315 & 30.34 & 4.15 & 0 \\
\hline SbPMEI11 & Sobic.002G102800 & III & $1-23$ & 555 & C.M & extr: 5 , vacu: 5 , chlo: 1 , cyto: 1 , plas: 1 & 184 & 18.64 & 6.24 & 0 \\
\hline SbPMEI12 & Sobic.002G103000 & III & $1-38$ & 579 & C.M & extr: 5, chlo: 4 , mito: 2, E.R._plas: 2 , plas: 1.5 & 198 & 20.15 & 4.86 & 0 \\
\hline SbPMEI13 & Sobic.003G099500 & I & $1-32$ & 639 & Nuc & chlo: 9 , mito: 2 , vacu: 2 & 212 & 23.01 & 10.39 & 0 \\
\hline SbPMEI14 & Sobic.003G099600 & I & $1-23$ & 477 & C.M & chlo: 9 , mito: 2 , extr: 2 & 158 & 17.11 & 5.72 & 0 \\
\hline SbPMEI15 & Sobic.003G100100 & I & $1-30$ & 603 & C.M, Nuc & chlo: 11 , vacu: 2 & 200 & 21.41 & 9.32 & 0 \\
\hline SbPMEI16 & Sobic.003G114800 & I & $1-25$ & 552 & C.M & extr: 5 , chlo: 3 , cyto: 3 , vacu: 2 & 183 & 19.92 & 9.10 & 0 \\
\hline SbPMEI17 & Sobic.003G114900 & I & $1-22$ & 507 & C.M & extr: 9 , vacu: 3 , chlo: 1 & 168 & 18.06 & 4.75 & 0 \\
\hline SbPMEI18 & Sobic.003G147700 & II & $1-42$ & 594 & C.M & $\begin{array}{l}\text { E.R.: 2.5, E.R._plas: } 2.5 \text {, chlo: 2, mito: } 2 \text {, extr: } \\
\text { 2, vacu: } 2 \text {, plas: } 1.5 \text {, nucl: } 1\end{array}$ & 213 & 22.19 & 4.57 & 1 \\
\hline SbPMEI19 & Sobic.003G203900 & III & $1-27$ & 570 & C.M & chlo: 4 , extr: 4 , vacu: 4 , mito: 1 & 189 & 19.61 & 9.50 & 0 \\
\hline SbPMEI20 & Sobic.003G270700 & I & $1-25$ & 657 & C.M & chlo: 9 , extr: 4 & 218 & 22.85 & 4.62 & 1 \\
\hline SbPMEI21 & Sobic.004G002700 & I & $1-37$ & 642 & C.M & extr: 8 , plas: 2 , golg: 2 , chlo: 1 & 213 & 23.48 & 9.00 & 0 \\
\hline SbPMEI22 & Sobic.004G002800 & II & $1-40$ & 720 & C.M & $\begin{array}{c}\text { chlo: 3, mito: 2, vacu: } 2 \text {, E.R.: } 2 \text {, nucl: } 1 \text {, cyto: } \\
\text { 1, plas: } 1 \text {, extr: } 1\end{array}$ & 239 & 25.16 & 4.79 & 0 \\
\hline SbPMEI23 & Sobic.004G147700 & III & $1-25$ & 558 & C.M & vacu: 7, E.R.: 3, plas: 2 , extr: 2 & 185 & 19.22 & 5.09 & 0 \\
\hline SbPMEI24 & Sobic.004G167700 & III & $1-27$ & 570 & C.M & extr: 9, chlo: 2 , vacu: 2 & 189 & 19.62 & 5.07 & 0 \\
\hline SbPMEI25 & Sobic.004G167800 & III & $1-35$ & 600 & C.M & chlo: 13 & 199 & 20.66 & 5.89 & 0 \\
\hline SbPMEI26 & Sobic.004G167900 & III & $1-22$ & 543 & C.M & extr: 13 & 180 & 18.85 & 5.43 & 0 \\
\hline SbPMEI27 & Sobic.004G168000 & III & $1-25$ & 513 & C.M & extr: 10 , chlo: 1 , mito: 1 , vacu: 1 & 170 & 18.17 & 5.90 & 1 \\
\hline SbPMEI28 & Sobic.004G277100 & I & $1-19$ & 543 & C.M & extr: 6 , chlo: 3 , vacu: 3 , nucl: 1 & 180 & 18.79 & 4.46 & 0 \\
\hline SbPMEI29 & Sobic.004G277600 & I & $1-27$ & 537 & C.M & chlo: 8 , extr: 5 & 178 & 18.87 & 4.98 & 0 \\
\hline SbPMEI30 & Sobic.004G277700 & I & $1-26$ & 546 & Nuc & extr: 12 , chlo: 1 & 183 & 18.91 & 5.45 & 0 \\
\hline SbPMEI31 & Sobic.005G022600 & III & $1-23$ & 588 & C.M & extr: 11 , chlo: 1 , cyto: 1 & 193 & 19.47 & 6.09 & 0 \\
\hline SbPMEI32 & Sobic.005G160700 & II & $1-30$ & 696 & C.M & chlo: 13 & 231 & 23.52 & 8.42 & 0 \\
\hline SbPMEI33 & Sobic.005G212900 & I & $1-24$ & 1707 & Nuc & vacu: 7 , nucl: 2 , extr: 2 , golg: 2 & 568 & 59.99 & 5.26 & 0 \\
\hline SbPMEI34 & Sobic.006G004300 & II & $1-27$ & 645 & C.M & chlo: 7 , extr: 3 , vacu: 3 & 214 & 22.83 & 10.66 & 0 \\
\hline SbPMEI35 & Sobic.006G079100 & I & $1-21$ & 660 & C.M & extr: 9, vacu: 3 , chlo: 2 & 219 & 22.88 & 8.24 & 0 \\
\hline SbPMEI36 & Sobic.006G094000 & III & $1-57$ & 714 & C.M & chlo: 10, mito: 3 & 237 & 25.01 & 9.47 & 0 \\
\hline SbPMEI37 & Sobic.006G194800 & I & $1-21$ & 567 & C.M & chlo: 6 , extr: 6 , cyto: 1 & 188 & 19.84 & 6.42 & 0 \\
\hline
\end{tabular}


Table 1. Cont

\begin{tabular}{|c|c|c|c|c|c|c|c|c|c|c|}
\hline \multirow{2}{*}{ Gene Name } & \multirow{2}{*}{ Sequence ID } & \multirow{2}{*}{ Subfamily } & \multirow{2}{*}{$\begin{array}{c}\text { Signal } \\
\text { Position }\end{array}$} & \multirow{2}{*}{ ORF (bp) } & \multicolumn{2}{|r|}{ Subcellular Localization } & \multicolumn{3}{|c|}{ Predicted Features } & \multirow{2}{*}{$\begin{array}{l}\text { No. of } \\
\text { Intron }\end{array}$} \\
\hline & & & & & Plant-mPLoc & WOLF PSORT & Length (aa) & NM (kDa) & pI & \\
\hline SbPMEI38 & Sobic.006G194900 & I & $1-21$ & 534 & C.M & extr: 8 , chlo: 4 , nucl: 1 & 177 & 18.27 & 6.72 & 0 \\
\hline SbPMEI39 & Sobic.007G008000 & I & $1-25$ & 723 & C.M, Nuc & chlo: 13 & 240 & 23.74 & 7.69 & 0 \\
\hline SbPMEI40 & Sobic.007G008100 & I & $1-25$ & 681 & C.M, Nuc & chlo: 12 , cyto: 1 & 226 & 22.94 & 8.32 & 0 \\
\hline SbPMEI41 & Sobic.007G008200 & I & $1-18$ & 660 & C.M & chlo: 12 , mito: 1 & 219 & 21.84 & 6.99 & 0 \\
\hline SbPMEI42 & Sobic.007G036000 & I & $1-24$ & 537 & C.M & extr: 10 , chlo: 1 , plas: 1 , vacu: 1 & 178 & 18.77 & 4.51 & 0 \\
\hline SbPMEI43 & Sobic.007G036200 & I & $1-24$ & 552 & Nuc & extr: 11 , chlo: 1 , vacu: 1 & 183 & 20.05 & 5.19 & 0 \\
\hline SbPMEI44 & Sobic.008G129800 & I & $1-31$ & 684 & C.M & extr: 10 , chlo: 1 , cyto: 1 , mito: 1 & 227 & 23.45 & 9.17 & 0 \\
\hline SbPMEI45 & Sobic.008G154500 & III & $1-22$ & 507 & C.M & chlo: 10 , cyto: 3 & 180 & 17.97 & 5.28 & 0 \\
\hline SbPMEI46 & Sobic.008G154600 & III & $1-19$ & 555 & C.M & extr: 11, vacu: 3 & 184 & 18.65 & 4.59 & 0 \\
\hline SbPMEI47 & Sobic.008G154700 & III & $1-26$ & 591 & C.M & extr: 8 , chlo: 3 , cyto: 2 & 196 & 19.03 & 5.71 & 0 \\
\hline SbPMEI48 & Sobic.008G154801 & III & $1-49$ & 711 & Nuc & $\begin{array}{l}\text { chlo: } 5 \text {, cyto: } 2 \text {, mito: } 2 \text {, nucl: } 1 \text {, plas: } 1 \text {, extr: } 1 \text {, } \\
\text { vacu: } 1\end{array}$ & 237 & 23.96 & 6.58 & 1 \\
\hline SbPMEI49 & Sobic.008G154900 & III & $1-23$ & 576 & C.M & chlo: 5 , extr: 5 , cyto: 2 , mito: 1 & 191 & 18.71 & 4.90 & 0 \\
\hline SbPMEI50 & Sobic.009G091600 & I & $1-30$ & 555 & C.M & extr: 7 , chlo: 3 , vacu: 3 & 184 & 19.99 & 9.24 & 0 \\
\hline SbPMEI51 & Sobic.009G216400 & III & $1-24$ & 567 & C.M, Nuc & extr: 8 , vacu: 4 , chlo: 1 & 188 & 20.66 & 5.83 & 1 \\
\hline SbPMEI52 & Sobic.010G006900 & II & $1-31$ & 567 & C.M & extr: 13 & 188 & 19.46 & 5.36 & 1 \\
\hline SbPMEI53 & Sobic.010G007600 & I & $1-26$ & 708 & Nuc & extr: 5 , chlo: 4 , vacu: 4 & 235 & 25.08 & 4.93 & 0 \\
\hline SbPMEI54 & Sobic.010G261000 & II & $1-21$ & 609 & C.M & chlo: 6 , extr: 3 , cyto: 2 , vacu: 2 & 202 & 20.55 & 9.35 & 0 \\
\hline SbPMEI55 & Sobic.010G261100 & II & $1-29$ & 654 & C.M & chlo: 14 & 217 & 21.62 & 9.60 & 0 \\
\hline
\end{tabular}

$\mathrm{ORF}=$ open reading frame; $\mathrm{MW}=$ molecular weight; $\mathrm{pI}=$ isoelectric point; chlo $=$ chloroplast $;$ extr $=$ extracellular matrix vacu $=$ vacuum; plas $=$ plasmid; E.R. $=$ endoplasmic reticulum;

E.R. plas = E.R. plasma; cyto $=$ cytoplasm; mito = mitochondrion; golg = Golgi apparatus; . $M=$ Cell membrane; Nuc/nucl = Nucleus . 
The length of PMEI protein sequences were generally two hundred aa, ranging from 158 aa of SbPMEI14 to 568 aa of SbPMEI33 with an average length of 205 aa, (Table 1). The molecular weight of the 55 SbPMEI proteins ranged from 17.11 to $59.99 \mathrm{kDa}$. The $\mathrm{pI}$ value ranged from 4.15 to 10.66 for all the SbPMEIs, which is absolutely a wide range. Moreover, all the SbPMEI proteins contained signal peptides, ranging from 16 to 57 amino acids in length. Each protein contains a signal position in the 50 aa N-terminal (Table 1), and 22 SbPMEIs contain a transmembrane domains (Figure 4), which is required for targeting to cell walls. WoLF PSORT II and Plant-mPLoc were used to predict the subcellular location, shown that SbPMEI proteins were mainly localized in the cell membrane and extracellular matrix, suggesting that most of PMEI proteins may be involved in the modification of cell wall during the cell wall synthesis and modification processes.
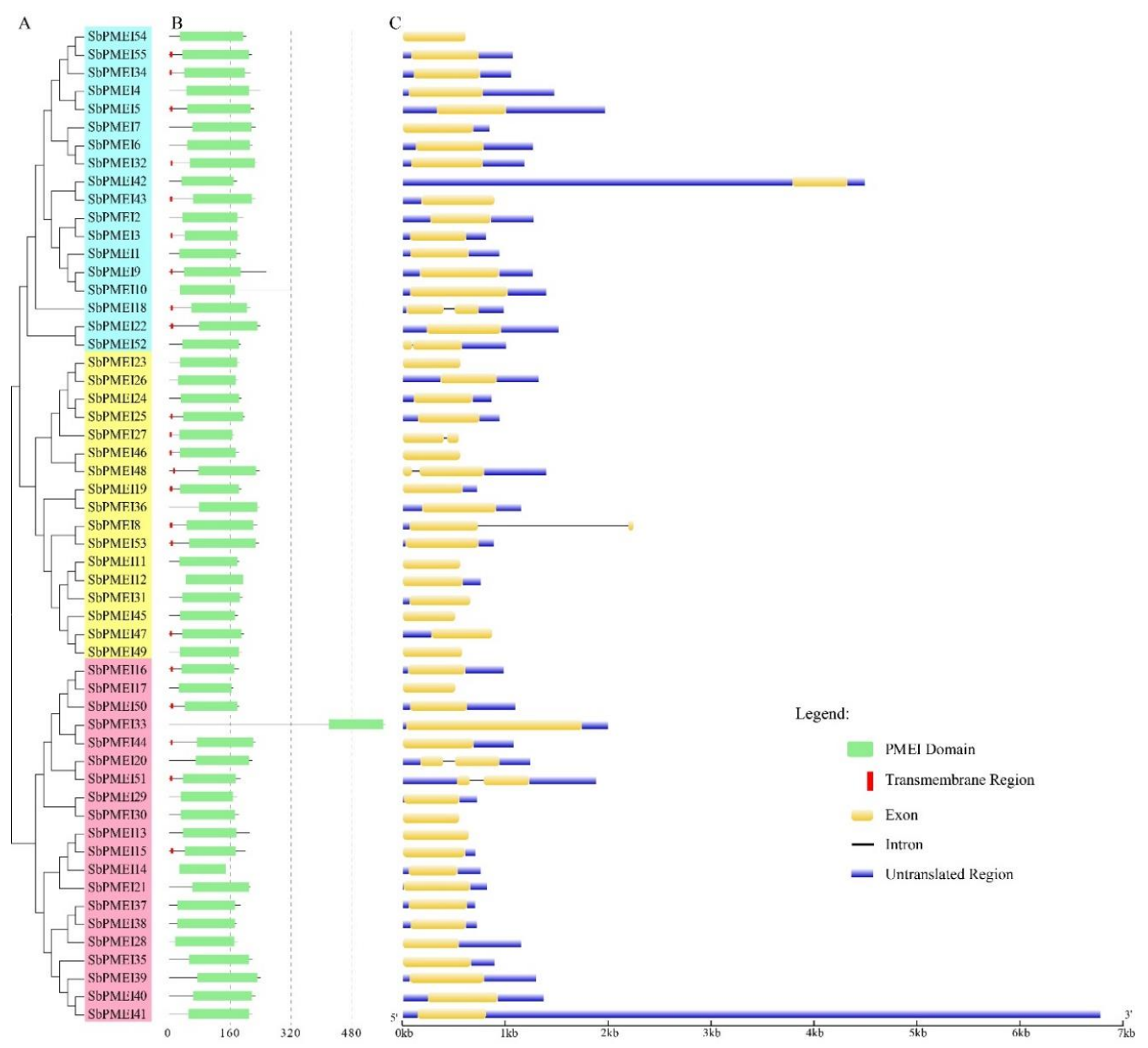

Figure 4. The NJ tree, the conserved domain in 55 SbPMEI proteins and the gene structures of sorghum 55 PMEI genes. (A) NJ phylogenetic tree by aligning the PMEI protein sequences of sorghum. (B) PMEI conserved domains (green rectangle) are presented in each PMEI proteins and transmembrane regions (red rectangle) are presented in 22 PMEI proteins of sorghum. (C) Gene structure of each SbPMEI. Exons and untranslated regions are presented by yellow and blue boxes, respectively. While, introns are presented by black lines.

\subsection{Gene Structure Analysis of SbPMEIs}

To investigate the gene homology relationship, the NJ tree was generated of SbPMEI proteins and three subfamilies were identified accordingly (Figures $3 \mathrm{C}$ and $4 \mathrm{~A}$ ). Each protein contained the PMEI conserved domain and some also contains transmembrane region in N-terminal to help the protein target on cell walls (Figure 4B). Gene structures of the SbPMEIs were obtained by comparing the predicted CDS with their corresponding genomic DNA sequences using GSDS (Figure 4C). 
As previous reported, most PMEI genes usually contain only one exon in many species, while 1.25 and 1.12 exons on average were detected in Arabidopsis and rice respectively [29]. Expectedly, such events were also observed in sorghum, only seven out of 55 SbPMEIs genes had two exons and the SbPMEI genes contained 1.12 exons on average. Interestingly, SbPMEI8 had a very long intron region as compared other SbPMEIs (Figure 4C). Members of SbPMEIs containing intron regions had been found in each subfamily. These results showed that the PMEIs in sorghum and rice were more conserved in gene structure than Arabidopsis [41].

\subsection{GO Analysis and Protein-Protein Interaction Prediction}

In order to further analyze the protein function of SbPMEI, category annotation was analyzed using Interpro Scan 5 (Supplementary File 6). Each sorghum, Arabidopsis and rice PMEI protein was annotated with GO: 0004857, which was displayed as "enzyme inhibitor activity" and was defined as "Molecular Function", suggesting that all mature PMEI proteins have a function of preventing or reducing the activity of an enzyme, which points to PME in plant, and it proved the accuracy of identifying the PMEI genes in sorghum (Supplementary File 6).

In order to investigate the co-expression genes with PMEI in sorghum, all members detected the protein-protein interaction. We found that only SbPMEI28 and SbPMEI35 showed an interaction with each other among $55 \mathrm{SbPMEIs.} \mathrm{When} \mathrm{proteins} \mathrm{were} \mathrm{checked} \mathrm{individually} \mathrm{for} \mathrm{their} \mathrm{interaction} \mathrm{networks,}$ SbPMEI18 showed interaction with various proteins with Synaptobrevin and KISc domain, which play important roles in intercellular transport of organelles especially from endoplasmic reticulum to Golgi apparatus (Figure 5A, Supplementary File 7). SbPMEI21 interacted with three PME proteins, which might be the targets of SbPMEI21 during cell wall modification (Figure 5B, Supplementary File 7).
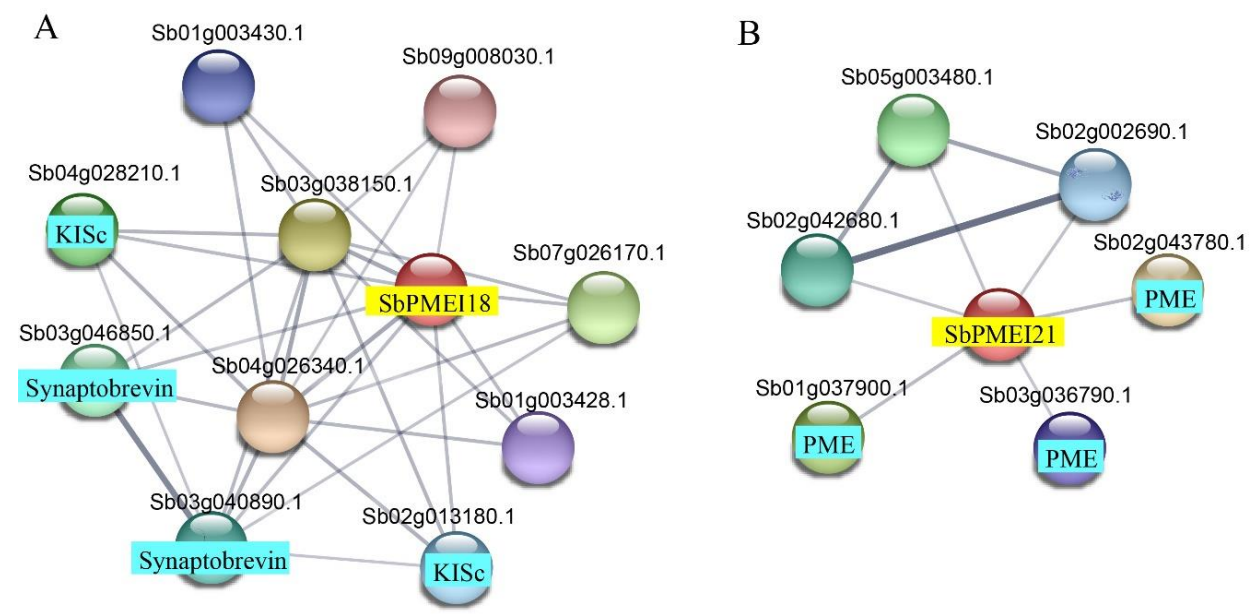

Figure 5. Protein-protein interaction networks of SbPMEI18 and SbPMEI21. (A) The interaction network of SbPMEI18. (B) The interaction network of SbPMEI21. The networks were generated from the STRING database. The red balls represented the queried protein while the other balls were the identifier. The annotation of the predicted protein was derived from UniProtKB (https://www.uniprot.org/). Line thickness indicates the strength of data support.

\subsection{Cis-Acting Elements Detection in Promoter Regions of SbPMEI Genes}

In order to further investigate the regulatory mechanism of SbPMEI genes, by PlantCARE, up to 88 kinds of cis-acting elements were detected in the $1.5 \mathrm{~kb}$ upstream regions of the identified SbPMEI genes, which might be useful to understand the regulatory cascade of the plant at different development stages under varying environmental factors. They are identified as: Light-responsive, hormone-responsive, environment stress-related, development-related, transcript factors binding sites and some elements of unknown function (Supplementary File 8). Most of those cis-elements appeared two or more times in 
the $1.5 \mathrm{~kb}$ promoter region of sorghum PMEI genes that was supposed to enhance their binding effects to their corresponding trans-acting factors (Figure 6).

A total of 24 light-responsive elements were detected, being the most abundant type in the upstream regions of PMEI genes. Among these, G-box and Box4 were the most abundant than the rest of others, which were detected in the promoters of 41 and 33 PMEI genes, respectively, occupying over 60 percent of the PMEI family members in sorghum. Moreover, each PMEI member contained one or more kinds of light-responsive elements. Among them, SbPMEI20 and SbPMEI45 contained eight kinds of such elements in their promoter regions. Whereas, SbPMEI5 and SbPMEI62 only contained G-box and sp1, respectively.
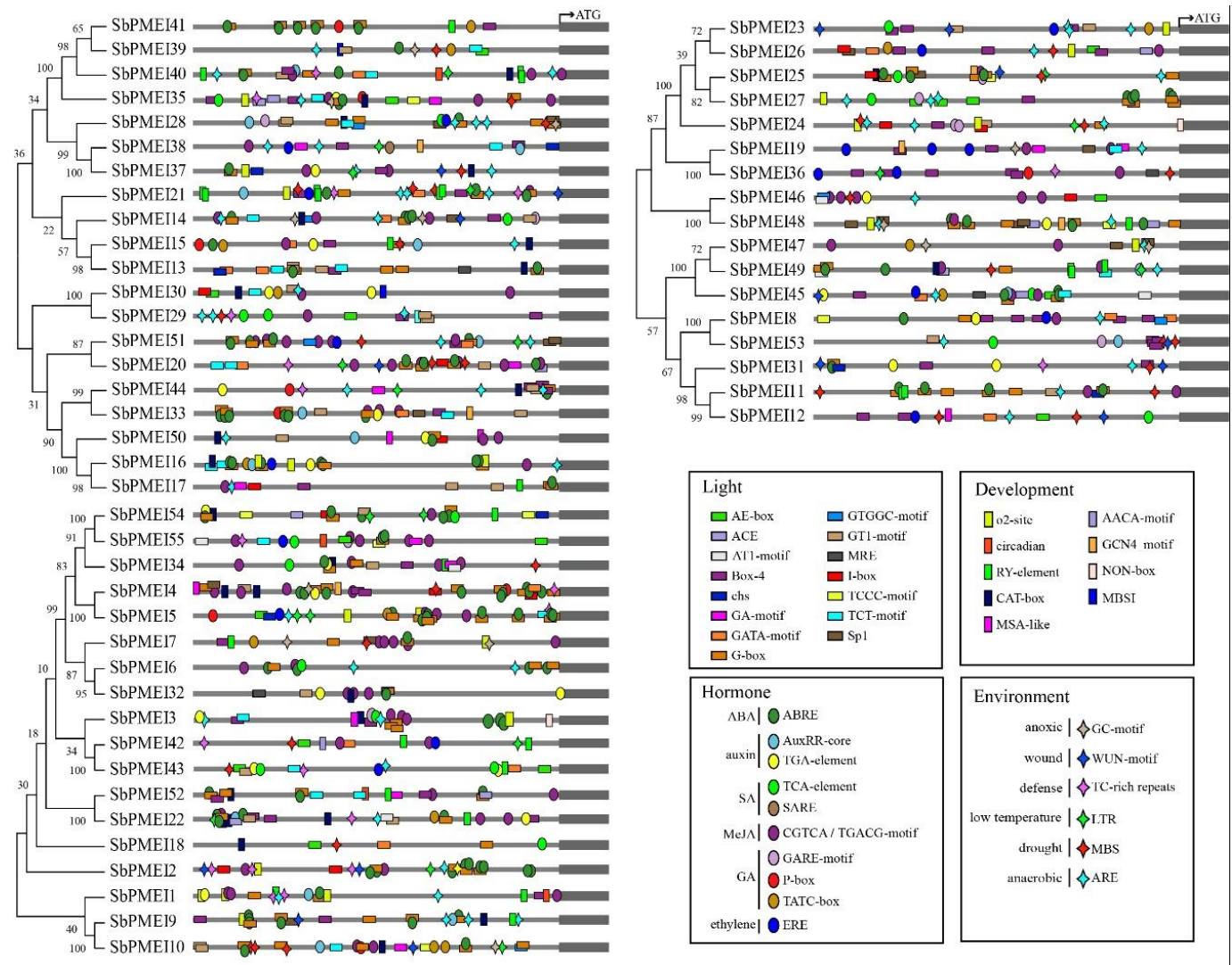

Figure 6. Cis-acting elements in the $1.5 \mathrm{~kb}$ promoter region of each PMEI gene of each subfamily in sorghum. $1.5 \mathrm{~kb}$ region before translation start codon (ATG) of each SbPMEI gene was analyzed by plant PlantCARE, and four major types of cis-acting elements were drawn above accordingly. The NJ phylogenetic tree was made with the proteins from the same subfamily.

Eleven plant hormone-responsive elements were detected in the upstream of 55 Sorghum PMEI genes, including ABRE (involved in the abscisic acid responsiveness), AuxRR-core (auxin responsiveness), GARE-motif, and P-box (gibberellin-responsive element), SARE (salicylic acid responsiveness), TATC-box (gibberellin-responsiveness), TCA-element (salicylic acid responsiveness element), TGA-element (auxin-responsive element), ERE (ethylene-responsive element) and CGTCA-motif/TGACG-motif (involved in the MeJA-responsiveness; Supplementary File 8). CGTCA-motif and TGACG-motif (the most abundant hormone-related elements) appeared at the same site and the opposite chains in the upstream regions of 42 gene members, followed by the ABRE element, which appeared in 40 SbPMEI genes. While, SARE appeared only in the promoter of SbPMEI38. SbPMEI12 while SbPMEI18 only had one copy of TGA and TCA-element, respectively. Whilst, SbPMEI24 had two repeats of GARE-motif. Eight types of hormone-related elements were found in the promoter region of SbPMEI45, containing the most kinds of hormone elements. 
The environmental stress-responsive elements were another important cis-acting type elements, which were detected in six different kinds. Unlike light and hormone-responsive elements, six SbPMEIs did not contain such elements in the promoters. As the most abundant environment-related element, ARE appeared in 39 members of PMEI family, especially in subfamily I and subfamily III, which is related to the anaerobic induction. Followed by MBS, a MYB binding site involved in drought-inducibility, occupied 27 SbPMEI genes.

Furthermore, the development-related element i.e., CAT-box was found to be located in the upstream regions of 19 SbPMEIs promoters, suggesting that these genes might involve in cell wall methylesterase/de-methylesterase modification during cell division. NON-box was another detected cis-acting regulatory element related to meristem specific activation, which only appeared in the promoter region of SbPMEI24. Sixteen PMEI genes contained the seed-specific regulation element in their promoter regions, RY-motif, suggesting their role in seed development.

\subsection{Expression Patterns of PMEI Genes in Growth Lifecycle}

The RNA-seq online data was used to analyze the SbPMEI genes expression patterns in 47 different tissues at different developmental stages throughout the sorghum lifecycle [37]. Heat map depicted the hierarchical clustering that was further used to analyze the expression profiles of 55 SbPMEI genes (Figure 7).

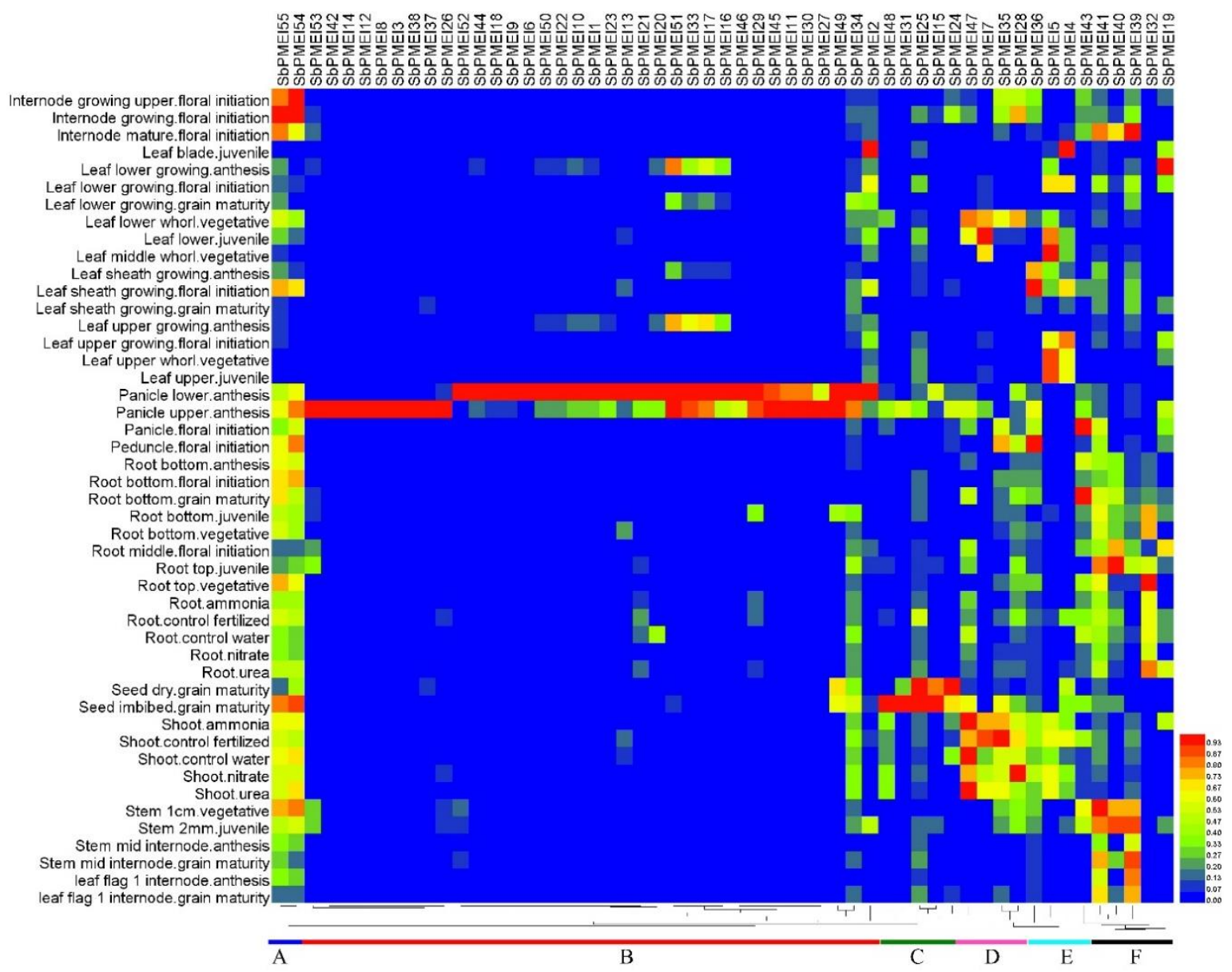

Figure 7. Heat map of 55 PMEIs in 47 tissues at different growth and developmental stages. The heat map shows the relative abundances of expressed genes. It ranges from low abundance (blue) to medium abundances (green) and high abundance (red). According to the expression patterns, six clusters (A-F) were classified. 
The expression patterns of SbPMEIs were divided into six distinct clusters (A-F), according to the heat map (Figure 7). Cluster A comprised of two genes, SbPMEI54 and SbPMEI55, belonging to subfamily II, showed highly expressed in internode than other genes and low expression in leaf. Whereas, cluster B consisted of thirty-four genes, which showed a very high expression level in panicle. While, SbPMEI11, SbPMEI12, SbPMEI14, SbPMEI27, SbPMEI45 and SbPMEI46 were found as the panicle-special expression genes. Genes in cluster $C$ were highly seed related expressed genes, including SbPMEI15, SbPMEI24, SbPMEI25, SbPMEI31 and SbPMEI48. Four genes constituted the cluster D and E, mainly imploded in leaf and shoot tissues. While cluster F, showed high accumulated level in stem and roots.

\subsection{Expression Patters of SbPMEIs under Exogenous Hormones and Abiotic Stresses}

Based on the analysis above, eight SbPMEIs were selected randomly to analyze the expression pattern under exogenous hormones or abiotic stress treatment, including MeJA, GA3, ABA, $\mathrm{H}_{2} \mathrm{O}_{2}$, PEG 6000 and $\mathrm{NaCl}$, using qRT-PCR, compared with treated at $0 \mathrm{~h}$ (Figure 8).

A

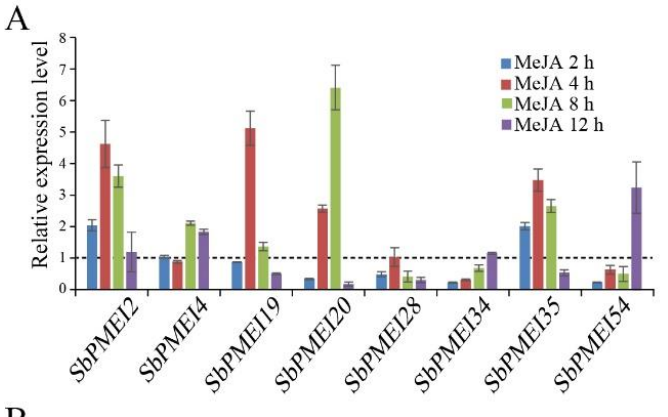

$\mathrm{B}$
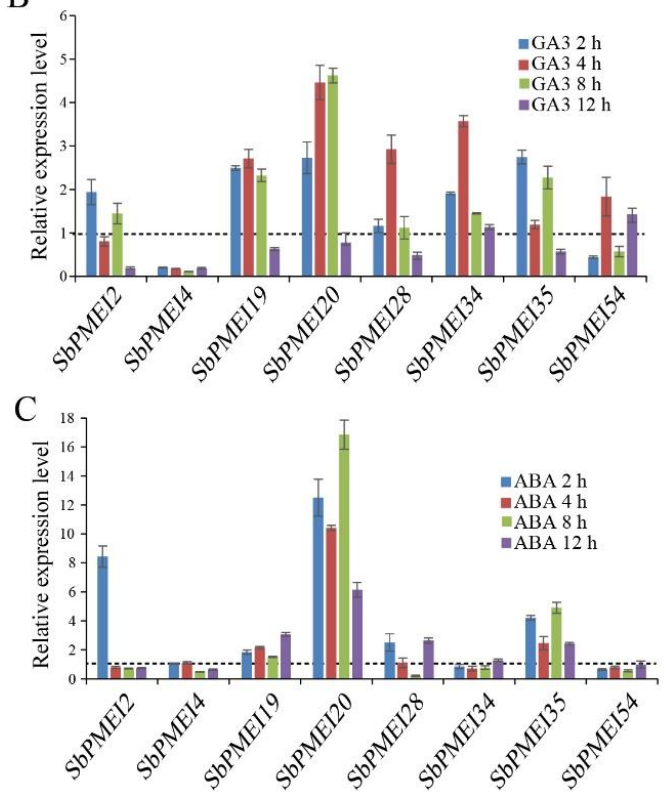

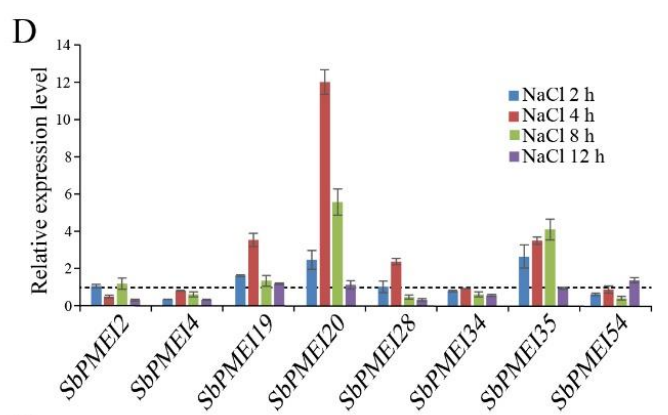

$\mathrm{E}$

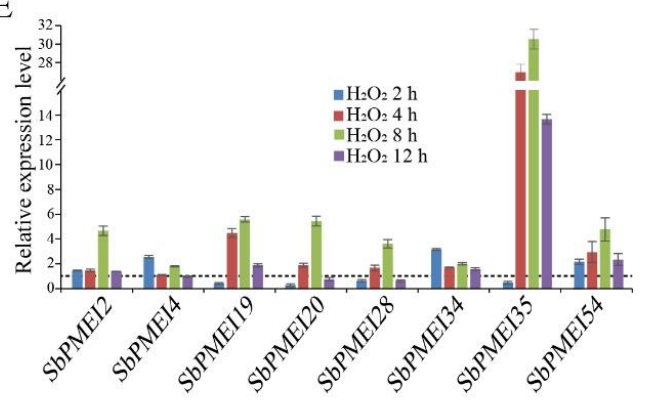

$\mathrm{F}$

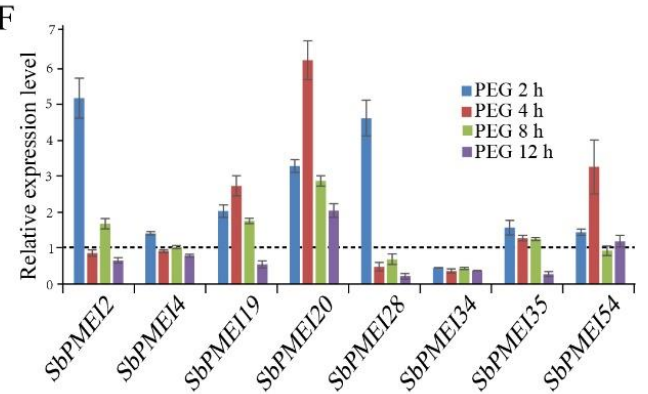

Figure 8. Relative expression levels of eight SbPMEIs involved in three exogenous hormones (A-C) and abiotic stresses (E-F) using qRT-PCR. Expression patterns treated by: (A) $100 \mu \mathrm{M} \mathrm{MeJA;} \mathrm{(B)} 100 \mu \mathrm{M}$ gibberellin A3; (C) $100 \mu \mathrm{M}$ of abscisic acid; (D) $250 \mathrm{mM} \mathrm{NaCl}$; (E) $100 \mathrm{mM}$ hydrogen peroxide and (F) $25 \%(w / v)$ polyethylene glycol. The relative expression level of eleven SbPMEIs were calculated relative to treatment at $0 \mathrm{~h}$.

For exogenous hormone treatments, most SbPMEIs were found to be up-regulated, especially, under MeJA and GA3 treatments. The expression of SbPMEI2, SbPMEI19 and SbPMEI20 were significantly induced by MeJA and reached a peak after treated at $8 \mathrm{~h}$ and $12 \mathrm{~h}$, respectively (Figure $8 \mathrm{~A}-\mathrm{C}$ ). For GA3 
treatment, most of the SbPMEI transcript accumulated after $2 \mathrm{~h}$, reaching a peak after $4 \mathrm{~h}$ and declined thereafter. The expression level of SbPMEI4 was significantly reduced when treated by GA3. ABA strongly increased the expression of SbPMEI2 at $2 \mathrm{~h}$ and then declined gradually. While SbPMEI20 was observed at a higher level at $2 \mathrm{~h}$ that was slightly reduced after $4 \mathrm{~h}$, then peaked at $8 \mathrm{~h}$. All the expression compared with control.

Abiotic stresses analysis showed that $\mathrm{NaCl}$ stress induced the expression of detected SbPMEIs, especially, SbPMEI20 and SbPMEI35. The expression of the two genes were induced at $2 \mathrm{~h}$ and got a peak at $4 \mathrm{~h}$, then reduced thereafter (Figure $8 \mathrm{E}-\mathrm{G}$ ). For $\mathrm{H}_{2} \mathrm{O}_{2}$ treatment, SbPMEI35 was the most sensitive gene to $\mathrm{H}_{2} \mathrm{O}_{2}$ amongst the detected SbPMEIs. Most of the detected genes were expressed highly at $8 \mathrm{~h}$ in response to $\mathrm{H}_{2} \mathrm{O}_{2}$ stress. Furthermore, the expression patterns of SbPMEIs that responded to drought stress treated by PEG, were induced at $2 \mathrm{~h}$ as compared with control (Figure $8 \mathrm{~F}$ ), suggesting that SbPMEIs were sensitive to drought. However, the expression level of SbPMEI34 was decreased at $12 \mathrm{~h}$, when treated by PEG. Taken together, the PMEI genes might play important roles in the stress response.

\section{Discussion}

PMEI proteins play an important role in pectin modification of cell walls. Since the first report in kiwifruit [11], PMEI family members have been identified in many plant species, including Triticum aestivum [38], Brassica oleracea [31], Linum usitatissimum [21] and so on. PMEI was found to be active against the activity of PME, to inhibit the cell wall de-methylesterified processes by forming a 1:1 complex. The identification of PMEI family is necessary to understand the modification of plant cell walls. Previous studies have demonstrated that PME activity affects the cell wall structure and plant phenotype, which is mainly regulated by $\mathrm{pH}$ and PMEI [2,3]. The increase of PME activity in the pmei6 mutant, resulted in the defective seed coat mucilage releasing [14]. Our previous study has reported that transcript factor MYB52 can activate the expression of PMEI14 to inhibit the PME activity in seed coat mucilage [12]. In this study, we monitored the PME activity in six sorghum tissues at the stage of one week after anthesis, which showed a great difference in different of tissues, e.g., lowest activity was detected in stem (Figure 1), that is quite contrary with the previous report of the highest level in fruit followed by stem tissues in tomato [42]. This indicates that PME activity varies between species. However, the high relative PME activity in leaf and leaf sheath might partly result from the low expression level of SbPMEIs in these tissues in Cluster A-D and F (Figures 1 and 7). Although most of the SbPMEIs were highly expressed in panicle at the stage of anthesis (Figure 7), the PME activity detected in panicle at the stage of anthesis after one week was still relatively high (Figure 1), suggesting that the PME activity might be differently regulated by PMEI transiently or regulated by complicated factors. The molecular mechanism of PME and PMEI should be further studied to explain the methylesterified modification of cell wall in different tissues of developmental stages in sorghum. When protein-protein interaction were detected by searching each SbPMEI individually, SbPMEI18 showed interaction with various proteins involved in intercellular transportation from endoplasmic reticulum to Golgi apparatus, which indicated that it might perform function in cell walls (Figure 5A). SbPMEI21 showed interaction with three PME proteins in sorghum, suggesting that SbPMEI21 may target one of those three PME to modify the cell wall through generating 1:1 non-covalent complex (Figure 5B, Supplementary File 7).

For decades, PMEs and PMEIs have been identified and reported in many species, 66 PMEs and 71 PMEIs in Arabidopsis [29], 79 PMEs and 48 PMEIs in tomato [42], 43 PMEs [43] and 49 PMEIs [29,44] in rice. According to previous report, 37 PMEIs and 23 PMEs were identified in Sorghum bicolor [29], and the number of PME family was confirmed [45]. However, in this study, a total of 55 PMEI proteins with PMEI conserved domain were identified in sorghum, using 49 rice and 71 Arabidopsis PMEI protein sequences to performing blastP in the JGI database (Figure 3, Table 1). The SMART and Pfam Tool were used to confirm each putative PMEI protein containing the PMEI domain (Figure 4B). Moreover, GO annotation analysis depicted that, each SbPMEI involved in the enzyme inhibiting 
activity (Supplementary File 6). According to the phylogenetic relationship, PMEIs in sorghum and rice clustered together, rather than with Arabidopsis (Figure 3A,B). Furthermore, the same event happened in gene structures (Figure 4C), containing 1.12 exons on average, same with rice and less than Arabidopsis with 1.25 exons on average, suggesting the gene structures in the monocot was more conserved. The sorghum PMEI members clustered into three subfamilies according to the NJ phylogenetic tree, which was supported by the gene structures, cis-acting elements and the expression pattern results (Figures 3, 4, 6 and 7). All of the genes were distributed among all ten sorghum chromosomes unevenly (Figure 2).

Gene expression pattern provides important clues for gene function, associated with the divergence of the promoter regions [31,46]. Cis-acting elements contained in the upstream region of genes play an important role in gene expression. For example, the transcriptional factor MYB52 belonging to the R2R3-MYB family, negatively regulates pectin de-methylesterification in seed coat mucilage, by binding the site of AA(A/C)AAAC in the promoter of PMEI6 and PMEI14 in Arabidopsis [12]. Therefore, we analyzed the cis-acting elements in the $1.5 \mathrm{~kb}$ upstream regions of the translation initiation codon of each sorghum PMEI gene, using PlantCARE. Six types of such elements were found in the promoter region (Supplementary File 8) and four types of functional elements were depicted and analyzed (Figure 6). Light-responsive elements were found more abundant with one of four most important cis-element types, while a total number of 24 . Among these, G-box was found in 41 promoters of SbPMEI genes. Besides this, eight kinds of light-responsive elements were also detected in the promoter regions of two SbPMEI genes (SbPMEI20 and SbPMEI60). However, little is known about the relationship between the expression of PMEI genes and light. In addition, eleven elements were involved with hormone treatment i.e., ABA, auxin, SA, MeJA, ethylene and GA, which is consistent with previous studies about PMEI genes in Brassica campestris [46]. The CGTCA/TGACG-motif (involved in MeJA) was found in 42 promoters, where ABRE appeared in 40 promoters, suggesting the large number of SbPMEIs might be induced by hormones. That is supported by Capsicum annuum, CaPMEI1 was induced by ABA, $\mathrm{H}_{2} \mathrm{O}_{2}$, PEG as well as cold [4]. Furthermore, most of the hormone-responsive elements appeared in the promoter of SbPMEI45. Up to 19 such elements were found in the promoter of SbPMEI4, out of which nine were related to ABA, eight with MeJA, while each element was related to GA and ABA (Figure 6). While, SbPMEI4 could be truly induced by MeJA and suppressed by GA and ABA, when treated by exogenous hormones (Figure 8A-C). Moreover, six different kinds of elements were detected involving the environmental response to anaerobic, anoxic, low temperature, drought, defense and wound. ARE involved in anaerobic, presented in 39 promoters. Additional, the MBS cis-element (MYB binding site involved in drought) was found in the promoters of 27 SbPMEI genes, where about half of the genes were similar to Brassica compestris [46]. SbPMEI20 was significantly induced by exogenous hormones, $\mathrm{NaCl}$ and PEG, containing $4 \mathrm{ABA}, 12 \mathrm{MeJA}$ and 2 MBS related elements in the promoter (Figures 6 and $8 \mathrm{~F}$ ), proposing an important role in hormone signaling and abiotic stress defense. Furthermore, as the most abundant element related to development, CAT-box, involved in meristem expression, was found in 19 promoters of SbPMEIs while 16 genes contained the RY-motif (seed-specific regulation element) in their promoter regions. qRT-PCR analyses were performed for three exogenous and three abiotic stress treatments, to analyze the expression profiles of eight SbPMEIs. However, only SbPMEI2, SbPMEI20, SbPMEI43 and SbPMEI35 were significantly induced by ABA treatment, similar to the CaPMEI1 [4], indicating that the expression profiles of most SbPMEIs differed among various treatments.

Moreover, the expression patterns of 55 SbPMEI genes were analyzed in 47 sorghum tissues at different growth and developmental stages with a heat map (Figure 7). The expression patterns were divided into six distinct clusters. Genes from the same cluster showed similar expression levels associated with different tissues or organs as well as different stages. Furthermore, the expression patterns differed among most $P M E I$ genes in each subfamily, which might functional differentiation after gene duplication events [30]. Members in cluster A, showed a high expression level in the internode, with a lower level in leaf and leaf sheath tissues at any developmental stage. Thirty-four 
SbPMEI genes of cluster B, showed high expression levels in panicle tissues while most of them showed relatively low expression in other tissues (Figure 7). Moreover, six genes were found as the panicle-special expression genes. That high expression level of over half PMEI family members in panicle did not result in low PME activity as expectedly (Figure 1), suggesting the regulation mechanism of PME activity might be complicated. Contrarily, fewer PMEI genes expressed highly in leaf and leaf sheath tissues, which might be the reason of a high-level PME activity in those tissues (Figures 1 and 7). However, no gene was detected expressing in all of the 47 tissues, which suggested that the expression patterns of PMEI genes were diverse.

\section{Conclusions}

Conclusively, a total of 55 PMEI genes in S. bicolor were identified and their molecular characterizations were analyzed. Molecular phylogeny of SbPMEIs along with 71 Arabidopsis and 49 rice PMEI members revealed that the gene evolution event occurred between monocot and dicot. Futhermore, the PMEI gene structures of sorghum and rice were more conserved than Arabidopsis. Each SbPMEI contained many cis-acting elements in their promoter region, revealing that the expression was controlled by a variety of factors i.e., light, plant hormone, stress, as well as transcriptional factors. Protein-protein interaction prediction shown SbPMEI21 interacted with three PME proteins, which might be the target of PMEI21 to generate 1:1 complex. The expression patterns of analyzed PMEIs using transcriptome data revealed that most of the SbPMEIs were highly expressed in panicle. However, though most SbPMEIs expressed highly in panicle, the PME activity in panicle was not detected as the lowest one comparing other tissues as expected. While a low expression level was detected in leaf and leaf sheath tissues, resulted in the high PME activity. In addition, the expression profiles to the exogenous hormone and abiotic stress treatment by qRT-PCR revealed that the majority of the PMEIs were induced by these stresses. Taken together, all the experimental and computational data analysis in this study, presented potentially advance understanding of the molecular and functional mechanism of PMEIs in S. bicolor, which will be fundamental in order to further study the cell wall of a considerably stable crop plant.

Supplementary Materials: The following are available online at http://www.mdpi.com/2073-4425/10/10/755/s1. Supplementary File 1: Primers list used in this study for qRT-PCR, Supplementary File 2: Genes identities of putative tandem duplicates, Supplementary File 3: Protein sequences of S. bicolor PMEIs, Supplementary File 4: Coding sequences of S. bicolor PMEIs, Supplementary File 5: Genomic sequences of S. bicolor PMEIs; Supplementary File 6: GO analysis for the PMEI genes in Sorghum, Arabidopsis and rice, Supplementary File 7: Protein-protein interaction prediction, Supplementary File 8: Cis-Acting elements analysis in the $1.5 \mathrm{~kb}$ promoters of sorghum PMEIs.

Author Contributions: Conceptualization, A.R., R.I.A., L.H. and Y.K.; Data curation, A.R., R.I.A., H.C., L.H. and A.D.; Writing —original draft preparation, A.R., R.I.A., J.S., and L.H.; Writing—review and editing, A.R., Y.G., and Y.K.; Visualization, A.R., L.H., and H.C.; Supervision, Y.G. and Y.K.; Project administration, A.D. and Y.K.

Funding: This research was funded by the National Natural Science Foundation of China (31670302 and 31470291). The National Key Technology R\&D Program (2015BAD15B03), and the Elite Youth Program of Chinese Academy of Agricultural Sciences (to Y.K.).

Conflicts of Interest: The authors declare no conflict of interest.

\section{References}

1. Zhao, Y.; Man, Y.; Wen, J.; Guo, Y.; Lin, J. Advances in Imaging Plant Cell Walls. Trends Plant Sci. 2019, 24, 867-878. [CrossRef] [PubMed]

2. Somerville, C.; Bauer, S.; Brininstool, G.M.; Facette, M.R.; Hamann, T.; Milne, J.S.; Osborne, E.; Paredez, A.R.; Persson, S.; Raab, T.K.; et al. Toward a systems approach to understanding plant-cell walls. Science 2004, 306, 2206-2211. [CrossRef] [PubMed]

3. Mohnen, D. Pectin structure and biosynthesis. Curr. Opin. Plant Biol. 2008, 11, 266-277. [CrossRef] [PubMed] 
4. An, S.H.; Sohn, K.H.; Choi, H.W.; Hwang, I.S.; Lee, S.C.; Hwang, B.K. Pepper pectin methylesterase inhibitor protein CaPMEI1 is required for antifungal activity, basal disease resistance and abiotic stress tolerance. Planta 2008, 228, 61-78. [CrossRef] [PubMed]

5. Zhang, G.; Feng, J.; Wu, J.; Wang, X. BoPMEI1, a pollen-specific pectin methylesterase inhibitor, has an essential role in pollen tube growth. Planta 2010, 231, 1323-1334. [CrossRef] [PubMed]

6. Wallace, S.; Williams, J.H. Evolutionary origins of pectin methylesterase genes associated with novel aspects of angiosperm pollen tube walls. Biochem. Biophys. Res. Commun. 2017, 487, 509-516. [CrossRef] [PubMed]

7. Verma, C.; Singh, R.K.; Mishra, S. Biochemical Characterization of Pectin Methylesterase from Musa acuminata Referring to Delayed Ripening. IOSR J. Pharm. Biol. Sci. 2014, 9, 42-47. [CrossRef]

8. Bosch, M.; Cheung, A.Y.; Hepler, P.K. Pectin methylesterase, a regulator of pollen tube growth. Plant Physiol. 2005, 138, 1334-1346. [CrossRef]

9. Al-Qsous, S.; Carpentier, E.; Klein-Eude, D.; Burel, C.; Mareck, A.; Dauchel, H.; Gomord, V.; Balange, A.P. Identification and isolation of a pectin methylesterase isoform that could be involved in flax cell wall stiffening. Planta 2004, 219, 369-378. [CrossRef] [PubMed]

10. Wormit, A.; Usadel, B. The Multifaceted Role of Pectin Methylesterase Inhibitors (PMEIs). Int. J. Mol. Sci. 2018, 19, 2878. [CrossRef]

11. Ciro, B.; Domenico, C.; Alfonso, G.; Lucio, Q.; Luigi, S. A glycoprotein inhibitor of pectin methylesterase in kiwi fruit (Actinidia chinensis). Eur. J. Biochem. 1990, 193, 183-187. [CrossRef]

12. Shi, D.; Ren, A.; Tang, X.; Qi, G.; Xu, Z.; Chai, G.; Hu, R.; Zhou, G.; Kong, Y. MYB52 Negatively Regulates Pectin Demethylesterification in Seed Coat Mucilage. Plant Physiol. 2018, 176, 2737-2749. [CrossRef]

13. Wolf, S.; Grsic-Rausch, S.; Rausch, T.; Greiner, S. Identification of pollen-expressed pectin methylesterase inhibitors in Arabidopsis. FEBS Lett. 2003, 555, 551-555. [CrossRef]

14. Saez-Aguayo, S.; Ralet, M.C.; Berger, A.; Botran, L.; Ropartz, D.; Marion-Poll, A.; North, H.M. PECTIN METHYLESTERASE INHIBITOR 6 promotes Arabidopsis mucilage release by limiting methylesterification of homogalacturonan in seed coat epidermal cells. Plant Cell. 2013, 25, 308-323. [CrossRef] [PubMed]

15. Sénéchal, F.; L'Enfant, M.; Domon, J.M.; Rosiau, E.; Crepeau, M.J.; Surcouf, O.; Esquivel-Rodriguez, J.; Marcelo, P.; Mareck, A.; Guerineau, F.; et al. Tuning of Pectin Methylesterification: PECTIN METHYLESTERASE INHIBITOR 7 modulates the processive activity of co-expressed PECTIN METHYLESTERASE 3 in a pH-dependent manner. J. Biol. Chem. 2015, 290, 23320-23335. [CrossRef] [PubMed]

16. Di Matteo, A.; Giovane, A.; Raiola, A.; Camardella, L.; Bonivento, D.; De Lorenzo, G.; Cervone, F.; Bellincampi, D.; Tsernoglou, D. Structural basis for the interaction between pectin methylesterase and a specific inhibitor protein. Plant Cell 2005, 17, 849-858. [CrossRef] [PubMed]

17. Sénéchal, F.; Mareck, A.; Marcelo, P.; Lerouge, P.; Pelloux, J. Arabidopsis PME17 Activity can be Controlled by Pectin Methylesterase Inhibitor 4. Plant Signal Behav. 2015, 10, e983351. [CrossRef]

18. Pelletier, S.; Van Orden, J.; Wolf, S.; Vissenberg, K.; Delacourt, J.; Ndong, Y.A.; Pelloux, J.; Bischoff, V.; Urbain, A.; Mouille, G.; et al. A role for pectin de-methylesterification in a developmentally regulated growth acceleration in dark-grown Arabidopsis hypocotyls. New Phytol. 2010, 188, 726-739. [CrossRef]

19. Müller, K.; Levesque-Tremblay, G.; Bartels, S.; Weitbrecht, K.; Wormit, A.; Usadel, B.; Haughn, G.; Kermode, A.R. Demethylesterification of Cell Wall Pectins in Arabidopsis Plays a Role in Seed Germination. Plant Physiol. 2013, 161, 305-316. [CrossRef]

20. Müller, K.; Levesque-Tremblay, G.; Fernandes, A.; Wormit, A.; Bartels, S.; Usadel, B.; Kermode, A. Overexpression of a pectin methylesterase inhibitor in Arabidopsis thaliana leads to altered growth morphology of the stem and defective organ separation. Plant Signal Behav. 2013, 8, e26464. [CrossRef]

21. Pinzón-Latorre, D.; Deyholos, M.K. Pectinmethylesterases (PME) and Pectinmethylesterase Inhibitors (PMEI) Enriched during Phloem Fiber Development in Flax (Linum usitatissimum). PLoS ONE 2014, 8, e105386. [CrossRef] [PubMed]

22. Reca, I.B.; Lionetti, V.; Camardella, L.; D'Avino, R.; Giardina, T.; Cervone, F.; Bellincampi, D. A functional pectin methylesterase inhibitor protein (SolyPMEI) is expressed during tomato fruit ripening and interacts with PME-1. Plant Mol. Biol. 2012, 79, 429-442. [CrossRef] [PubMed]

23. Lionetti, V.; Raiola, A.; Mattei, B.; Bellincampi, D. The Grapevine VvPMEI1 Gene Encodes a Novel Functional Pectin Methylesterase Inhibitor Associated to Grape Berry Development. PLoS ONE 2015, 10, e0133810. [CrossRef] [PubMed] 
24. Alfonso, C.; Ciro, B.; Lucio, Q.; Domenico, C.; Luigi, S. A glycoprotein inhibitor of pectin methylesterase in kiwi fruit Purification by affinity chromatography and evidence of a ripening-related precursor. Eur. J. Biochem. 1995, 233, 926-929. [CrossRef]

25. Lionetti, V.; Raiola, A.; Camardella, L.; Giovane, A.; Obel, N.; Pauly, M.; Favaron, F.; Cervone, F.; Bellincampi, D. Overexpression of pectin methylesterase inhibitors in Arabidopsis restricts fungal infection by Botrytis cinerea. Plant Physiol. 2007, 143, 1871-1880. [CrossRef] [PubMed]

26. Lionetti, V.; Fabri, E.; DeCaroli, M.; Hansen, A.R.; Willats, W.G.; Piro, G.; Bellincampi, D. Three Pectin Methylesterase Inhibitors Protect Cell Wall Integrity for Arabidopsis Immunity to Botrytis. Plant Physiol. 2017, 173, 1844-1863. [CrossRef]

27. Volpi, C.; Janni, M.; Lionetti, V.; Bellincampi, D.; Favaron, F.; D'Ovidio, R. The Ectopic Expression of a Pectin Methyl Esterase Inhibitor Increases Pectin Methyl Esterification and Limits Fungal Diseases in Wheat. Mol. Plant Microbe Interact. 2011, 24, 1012-1019. [CrossRef]

28. Tundo, S.; Kalunke, R.; Janni, M.; Volpi, C.; Lionetti, V.; Bellincampi, D.; Favaron, F.; D’Ovidio, R. PvPGIP2 Accumulation in Specific Floral Tissues but Not in the Endosperm Limits Fusarium graminearum Infection in Wheat. Mol. Plant Microbe Interact. 2016, 29, 629-639. [CrossRef]

29. Wang, M.; Yuan, D.; Gao, W.; Li, Y.; Tan, J.; Zhang, X. A comparative genome analysis of PME and PMEI families reveals the evolution of pectin metabolism in plant cell walls. PLoS ONE 2013, 8, e72082. [CrossRef]

30. Li, X.; Hamyat, M.; Liu, C.; Salman, A.; Gao, X.; Guo, C.; Wang, Y.; Guo, Y. Identification and Characterization of the WOX Family Genes in Five Solanaceae Species Reveal Their Conserved Roles in Peptide Signaling. Genes 2018, 9, 260. [CrossRef]

31. Liu, T.; Yu, H.; Xiong, X.; Yu, Y.; Yue, X.; Liu, J.; Cao, J. Genome-Wide Identification and Characterization of Pectin Methylesterase Inhibitor Genes in Brassica oleracea. Int. J. Mol. Sci. 2018, 19, 3388. [CrossRef] [PubMed]

32. Wang, M.; Xu, Z.; Ding, A.; Kong, Y. Genome-Wide Identification and Expression Profiling Analysis of the Xyloglucan Endotransglucosylase/Hydrolase Gene Family in Tobacco (Nicotiana tabacum L.). Genes 2018, 9 , 273. [CrossRef] [PubMed]

33. Hu, B.; Jin, J.; Guo, A.; Zhang, H.; Luo, J.; Gao, G. GSDS 2.0: An upgraded gene feature visualization server. Bioinformatics 2015, 31, 1296-1297. [CrossRef]

34. Hunter, S.; Apweiler, R.; Attwood, T.K.; Bairoch, A.M.; Bateman, A.; Binns, D.; Bork, P.; Das, U.; Daugherty, L.; Duquenne, L.; et al. InterPro: The integrative protein signature database. Nucleic Acids Res. 2009, 37, 211-215. [CrossRef] [PubMed]

35. Szklarczyk, D.; Franceschini, A.; Kuhn, M.; Simonovic, M.; Roth, A.; Minguez, P.; Doerks, T.; Stark, M.; Muller, J.; Bork, P.; et al. The STRING database in 2011: Functional interaction networks of proteins, globally integrated and scored. Nucleic Acids Res. 2011, 39, 561-568. [CrossRef] [PubMed]

36. Ding, A.; Marowa, P.; Kong, Y. Genome-wide identification of the expansin gene family in tobacco (Nicotiana tabacum). Mol. Genet. Genom. 2016, 291, 1891-1907. [CrossRef] [PubMed]

37. McCormick, R.F.; Truong, S.K.; Sreedasyam, A.; Jenkins, J.; Shu, S.; Sims, D.; Kennedy, M.; Amirebrahimi, M.; Weers, B.D.; McKinley, B.; et al. The Sorghum bicolor reference genome: Improved assembly, gene annotations, a transcriptome atlas, and signatures of genome organization. Plant J. 2018, 93, 338-354. [CrossRef]

38. Hong, M.; Kim, D.Y.; Lee, T.G.; Jeon, W.B.; Seo, Y.W. Functional characterization of pectin methylesterase inhibitor (PMEI) in wheat. Genes Genet. Syst. 2010, 85, 97-106. [CrossRef] [PubMed]

39. Sudhakar, R.P.; Srinivas, R.D.; Sivasakthi, K.; Bhatnagar-Mathur, P.; Vadez, V.; Sharma, K.K. Evaluation of Sorghum [Sorghum bicolor (L.)] Reference Genes in Various Tissues and under Abiotic Stress Conditions for Quantitative Real-Time PCR Data Normalization. Front. Plant Sci. 2016, 7, 529. [CrossRef]

40. Schmittgen, T.D.; Livak, K.J. Analyzing real-time PCR data by the comparative CT method. Nat. Protoc. 2008, 3, 1101-1108. [CrossRef]

41. Xu, G.; Guo, C.; Shan, H.; Kong, H. Divergence of duplicate genes in exon-intron structure. PNAS 2012, 109, 1187-1192. [CrossRef] [PubMed]

42. Jeong, H.Y.; Nguyen, H.P.; Eom, S.H.; Lee, C. Integrative analysis of pectin methylesterase (PME) and PME inhibitors in tomato (Solanum lycopersicum): Identification, tissue-specific expression, and biochemical characterization. Plant Physiol. Biochem. 2018, 132, 557-565. [CrossRef] [PubMed] 
43. Jeong, H.Y.; Nguyen, H.P.; Lee, C. Genome-wide identification and expression analysis of rice pectin methylesterases: Implication of functional roles of pectin modification in rice physiology. J. Plant Physiol. 2015, 183, 23-29. [CrossRef] [PubMed]

44. Nguyen, H.P.; Jeong, H.Y.; Kim, H.; Kim, Y.C.; Lee, C. Molecular and biochemical characterization of rice pectin methylesterase inhibitors (OsPMEIs). Plant Physiol. Biochem. 2016, 101, 105-112. [CrossRef] [PubMed]

45. Rai, K.; Thu, S.; Balasubramanian, V.; Cobos, C.; Disasa, T.; Mendu, V. Identification, Characterization, and Expression Analysis of Cell Wall Related Genes in Sorghum bicolor (L.) Moench, a Food, Fodder, and Biofuel Crop. Front. Plant Sci. 2016, 7. [CrossRef] [PubMed]

46. Liu, T.; Yu, H.; Xiong, X.; Yue, X.; Yu, Y.; Huang, L.; Cao, J. Genome-Wide Identification, Molecular Evolution, and Expression Profiling Analysis of Pectin Methylesterase Inhibitor Genes in Brassica campestris ssp. chinensis. Int. J. Mol. Sci. 2018, 19, 1338. [CrossRef] [PubMed]

(C) 2019 by the authors. Licensee MDPI, Basel, Switzerland. This article is an open access article distributed under the terms and conditions of the Creative Commons Attribution (CC BY) license (http://creativecommons.org/licenses/by/4.0/). 